\title{
2 Machine learning for the design and development of 3 biofilm regulators
}

\author{
4 Benjamin Stone and Erik Sapper*
}

Department of Chemistry and Biochemistry, California Polytechnic State University, San Luis Obispo, CA 93407. *Corresponding author: esapper@calpoly.edu

\begin{abstract}
Biofilms are congregations of bacteria on a surface, and they grow into obstacles for the functionalities of any device or machinery involves anything biological. Biofilms are developed through a biochemical system known as 'Quorum Sensing' that accounts for the chemical signaling that direct either biofilm formation or inhibition. Computational models that relate chemical and structural features of compounds to their performance properties have been used to aide in the discovery of active small molecules for many decades. These quantitative structure-activity relationship (QSAR) models are also important for predicting the activity of molecules that can have a range of effectiveness in biological systems. This study uses QSAR methodologies combined with and different machine learning algorithms to predict and assess the performance of several different compounds acting in Quorum Sensing. Through computational probing of the quorum sensing molecular interaction, new design rules can be elucidated for countering biofilms.
\end{abstract}
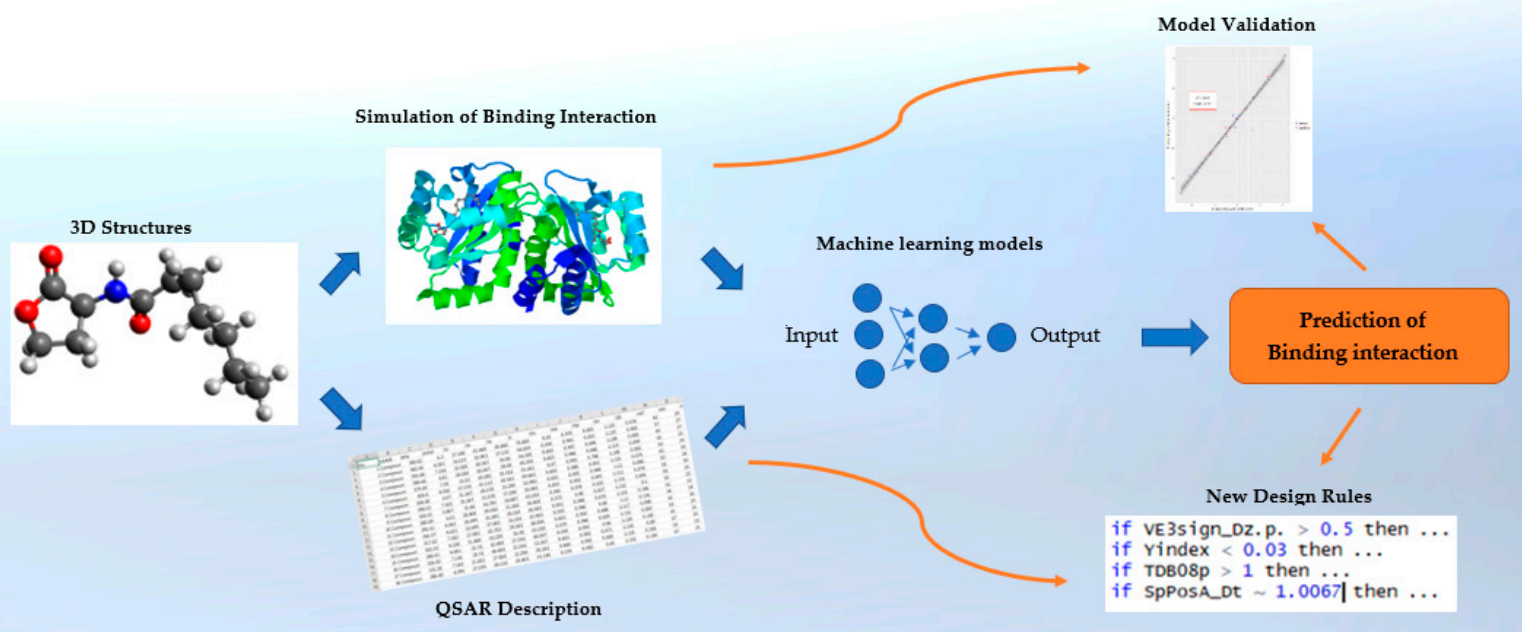

Figure 1. Graphical abstract of this study's workflow

Keywords: Machine Learning: Biochemistry; QSAR; Molecules; Neural Networks

\section{Introduction}

Biofilms are a buildup of bacteria that form on a surface and disperse bacteria colonies. Bacterium individually are known as 'planktonic' and exhibit individual locomotion, but once a certain population (or quorum) congregates on a surface, specific intracellular signals are produced [1]. This process is called 'Quorum sensing' (QS) and it consists of the chemical communications bacteria use to either turn on or turn off the biofilm formation and growth response. Chemical signals or 'quorum sensors' are part of the protein interactions causing the group of bacteria to switch their gene 
expression to one that facilitates biofilm regulation. These chemical signals are called auto-inducers [2]. Auto-inducers start the transcription process for biofilm-related genes. One protein of interest in QS is the LasR protein in the bacterial species, P. Aeruginosa. [2]. P. Aeruginosa is a bacteria model system exhibiting numerous genes that modulate the quorum response. The quorum response is not limited to only biofilms; there are multiple gene responses triggered by chemical signaling that can also modulate other bacteria behaviors such as virulence, bioluminescence production, conjugation, sporulation, and swarming motility [3]. Synthetic chemists have identified more potent derivatives of these chemical signals and labeled them as quorum sensing inhibitors (QSIs), to describe their effect in turning off the change in gene expression [4]. In the past 20 years, many articles across disciplines have been written about the synthesis of quorum sensing inhibitors, and how well they can inhibit the biofilm response. $\mathrm{N}$-acyl homo-serine lactones are another class of QSIs that bacteria produce themselves to modulate their group response [4]. These functionalized lactones and other classes of quorum sensing inhibitors have been synthesized and tested through cell-based assays to evaluate how well they perform at limiting bacterial congregation. A different class of multi-aromatic molecules, indoles, are known to modulate the quorum signaling response [5]. Indoles behave similarly to $\mathrm{N}$-acyl homo-serine lactones, due to their having much of the same structural, chemical and topographic features. An observation that could be easily seen by medicinal chemists is the common presence of the amide bonded to a cyclic ring. Shown in Table 1 are examples of these compounds, while a full list of relevant structures can be found in the Appendix A.

Table 1. Examples of quorum sensing inhibitors

\begin{tabular}{|l|c|c|}
\hline \multicolumn{2}{c|}{ Compound structure } & Compound Name \\
Geske [4]
\end{tabular}

The present study uses computational ligand-receptor docking data in tandem with machine learning algorithms to uncover design rules for quorum sensing chemical systems. Quantitative structure-activity relationship (QSAR) methods produce a large set of numerical descriptions for the chemical space that is desired. Medicinal chemists use these descriptors to interpret functional differences in structurally similar compounds [6]. Using the $\mathrm{R}$ statistical language and the caret machine learning package, these descriptor values will be processed for importance, and passed into a neural network for training and testing [7-8]. These neural networks are tuned, with other functions in the caret package, to predict how well these molecules bind to the target protein. The predicted modeling data will then be validated by a more computationally rigorous docking investigation. The models generated using QSAR descriptors are then tuned for the discovery of design rules that may aid as foundational new knowledge for discovering functional chemical spaces having the ability to control or modulate the biofilm response. 


\section{Materials and Methods}

A set of 37 molecules with known quorum sensing inhibition activity were selected from several literature sources [4-5]. Two-dimensional structures of these molecules were constructed in ChemDraw [9]. The two-dimensional files were converted to three-dimensional structure files using OpenBabel, an open source molecular file converter [10]. Mol2 and PDBQT files were used as input for QSAR descriptor calculation and molecular docking simulations, respectively. Structures of these molecules can be found in Appendix A, while structure files can be found in the online supplemental information.

The mol2 files of the compounds were input into DRAGON 7, a software that allows users to calculate all structure-activity related descriptors for given three-dimensional structures [11]. This software generated a table of comma separated values of the compounds and the values of all five thousand seven hundred and seventy-two descriptors calculated.

A crystalized protein structure of the LasR protein was found in the online protein data base from a crystallography study and downloaded from the online protein data base in the form of a PDBQT file [12-13]. Using autogrid4, the active site of the protein was visualized to assess the docking ability of all quorum sensing inhibitor candidates [14]. Using AutoDock, a binding simulation software, all inhibitors were docked in the active site of the LasR protein and spatially evaluated for computation of the binding affinity of the protein-inhibitor interaction [15]. Figure 2 shows the binding site that was evaluated in AutoDock.

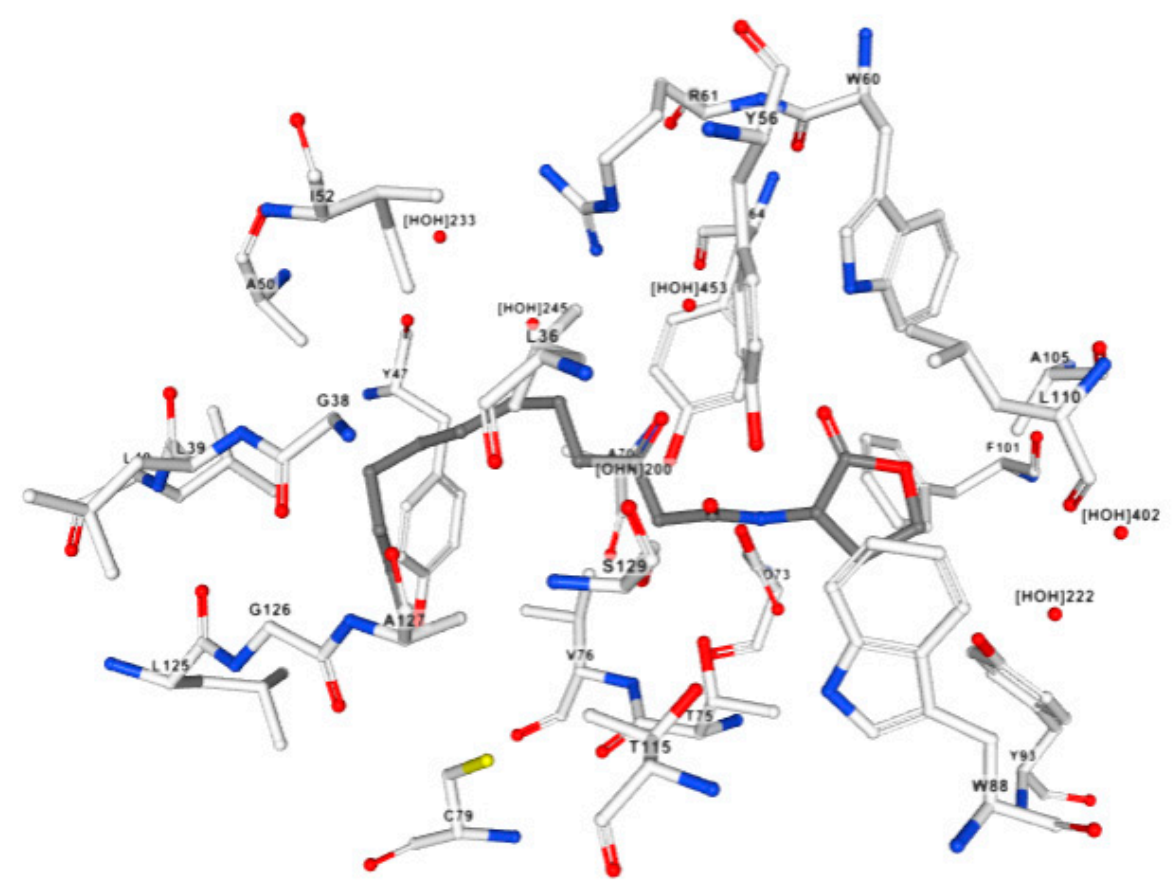

Figure 2. Figure of docking simulation between N-heptanoyl-L-homoserine lactone and the LasR complex [11]

The binding affinity represents how well each compound fits to the active site of the protein, which is a good predictor of how the interaction triggers a transcription event that regulates the biofilm response. The values of binding affinities generated can be found in Appendix B. Since these molecules successfully inhibit the protein by out-competing the natural ligand, the binding activity is a negative value. The binding affinity of these interactions were computed and can be seen in Figure 3. Binding affinity has units of kilojoules per mole and refers to the free energy liberated in the binding interaction between ligand and receptor. The negative affinity for the binding interaction indicates a stabilization of the protein. While both classes have similar ranges in binding affinity, the 
94 95

indole class has some outliers with a more negative and thus stronger binding affinity [5]. Figure 3 shows the ranges of binding affinity throughout the set of molecules.

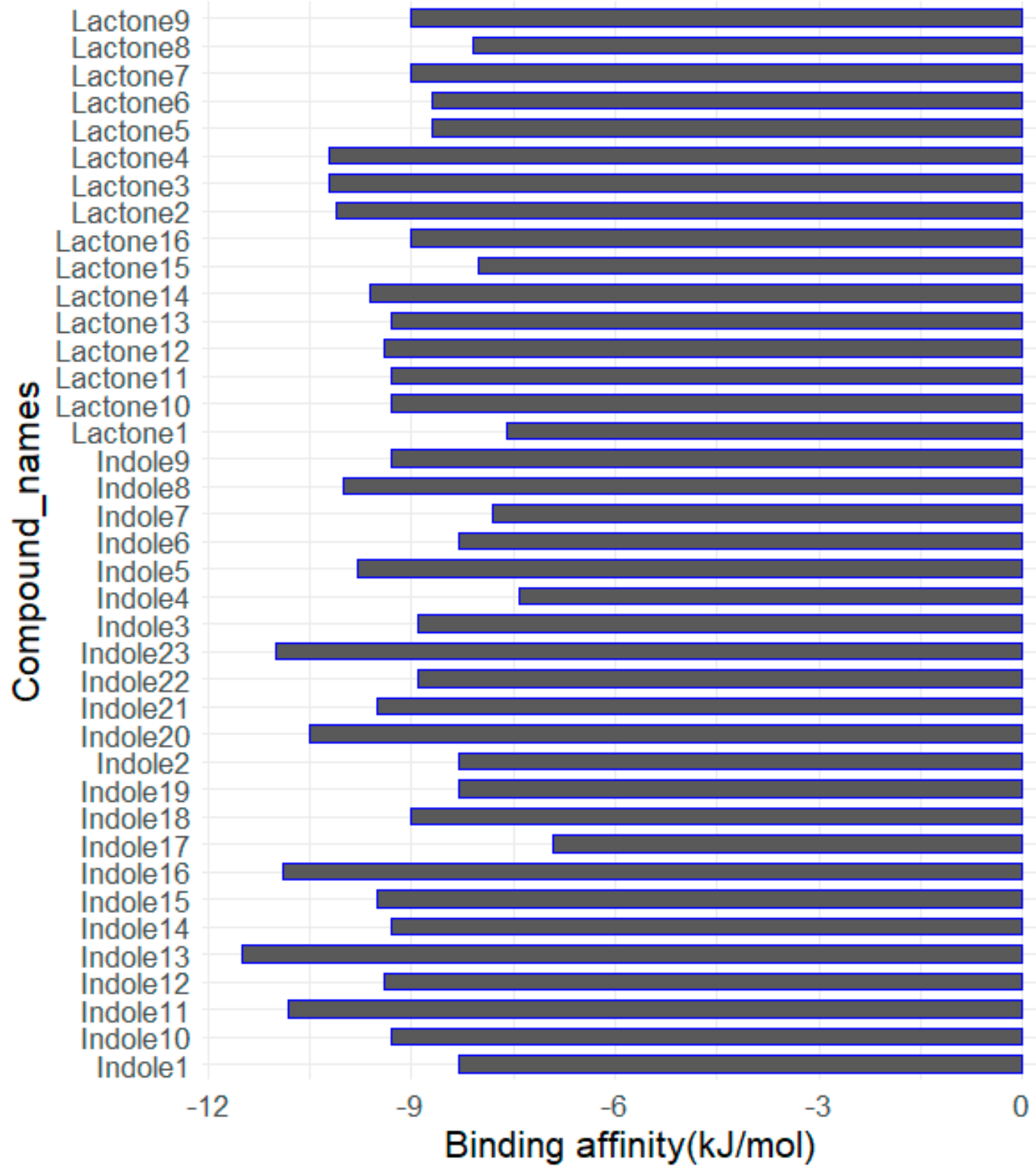

Figure 3. Bar graph of binding affinities calculated through AutoDock.

Binding affinities were appended onto the dataset of the QSAR descriptors for each molecule. The dataset was saved as a table of comma separated values and read into a data frame using the $R$ statistical language. $\mathrm{R}$ was used to find important variables, wrangle data, explore different models, test predictions, and to visualize data and models for evaluation of performance. The caret software package is utilized to control and tune the models that are appropriate to our dataset. [8] The caret software package, developed by Max Kuhn, allows users to choose from and adjust features of many different of classification and regression models with machine-learning features. Scripts demonstrating how these functions were implemented can be found in the online Supplemental Material.

Initially, the dataset is split by molecule class using the nO descriptor, which is number of oxygen atoms found in the molecule. The defining rule for descriptor split is that the lactone class has one or two oxygen atoms, while the indole class has three or more oxygen atoms per molecule. Separating these classes of molecules and having two different models allows for elucidation of descriptors specific to each molecule class that drive the binding affinity of the molecule. Since the two models account for different descriptors in each class, the molecules in each class must have their 
113 own training and testing data. The createDataParition() function in caret allows for the

114

115

116

117

118

119

120

121

122

123

124

125

126

127

128

129

130

131

132

133

134

135

136

137

138

139

140

141

142

143

144

145

146

147

148

149

150

151

152

153

154

155

156

157

158

159

160 random splitting of data used to train and test neural networks. The argument $p$ of the function is set as 0.7 , indicating that $70 \%$ of the molecules are used for training the networks, while the remaining $30 \%$ are used for validation of the model, ensuring that the model is learning about patterns of the descriptor sets in the molecules.

To draw conclusions about which descriptors are integral for the functionality of the ligand binding interaction, only relevant data should be considered for model input. Many QSAR studies utilize numerical correlations or principal component analysis between each descriptor and its binding to find which descriptors have predictive capabilities, but caret allows us to use other options. A caret function called $\mathrm{nzv}()$ is used to drop the descriptor values that have near zero variance between molecules. The $\mathrm{nzv}()$ function removes variables that are all 0 for the set of molecules, thereby removing unimportant or uninformative descriptors. The recursive feature elimination function, $r f e()$, in caret, is a backwards selection algorithm that uses a random forest model to find the descriptors that serve as good predictors. In the $r f e()$ function, multiple random forest models are performed, and descriptors are ranked by their importance to the model. After each iteration of the forest, the most important descriptors are retained and used to fit the next model. The algorithm allows for selection of a specific number of descriptors for each molecule class.

QSAR and machine learning studies can use myriad different model-building algorithms such as linear regression, random forests, support vector machines, and neural networks. Difference between these models can be shown in the results subsection of this paper, Model Selection. Neural networks are well-suited for QSAR studies because each descriptor can serve as an input to be evaluated by the network. These inputs are used in multiple layers of functions utilizing linear algebra to find the best function for the machine to learn how to predict binding affinity effectively. For good model performance, it is important for each component of the model to be evaluated under the condition of Bayesian methods [16]. Bayes' rule is used to ensure that the statistical importance of each descriptor is weighed independently, making models more robust and less prone to overfitting [17].

The QSAR datasets are constrained to the important variables found from the rfe ( ) and input into a caret train object used to train a Bayesian-regularized neural network. Caret allowed for quick tuning based on the number of neurons, weighting of variables at different points in the network, amount of resampling, and cross-validation. To insure accuracy of these networks, each neuron was input from a singular variable of a molecular descriptor. The output of these models is the predicted binding affinities based on the QSAR descriptors. To validate the methodology, these outputs can be compared to the binding affinity predicted by the docking simulation. The models, once validated, allow for the elucidation of important structural and topographic features driving the binding interaction.

\section{Results}

\subsection{Model Selection}

A variety of models can be used for QSAR, but some models are more ideal for appropriate for characterization of the QS interaction. Caret allows for fast testing of different machine learning models. Bayesian regularized artificial neural networks (BRANN) suit QSAR methodologies well due to their reliance on individual descriptors. BRANNs tend to generalize features found in the descriptions, creating more accurate predictions for the test data. Many QSAR-based machine learning models rely on generalizing the dataset by though Bayesian methods for accurate prediction of the molecular interaction of interest [17]. The QS activation of the LasR interaction can be modeled through BRANNs. Figure 4 shows the statistical differences between each model establishing the higher relative performance of BRANNs. These networks exhibited high performance through an increase in the R-squared value and a decrease in both the means average error and RMSE. 


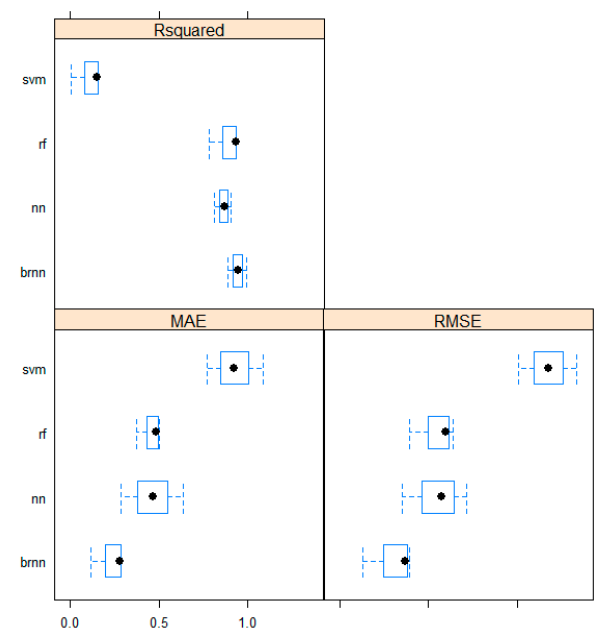

(a)

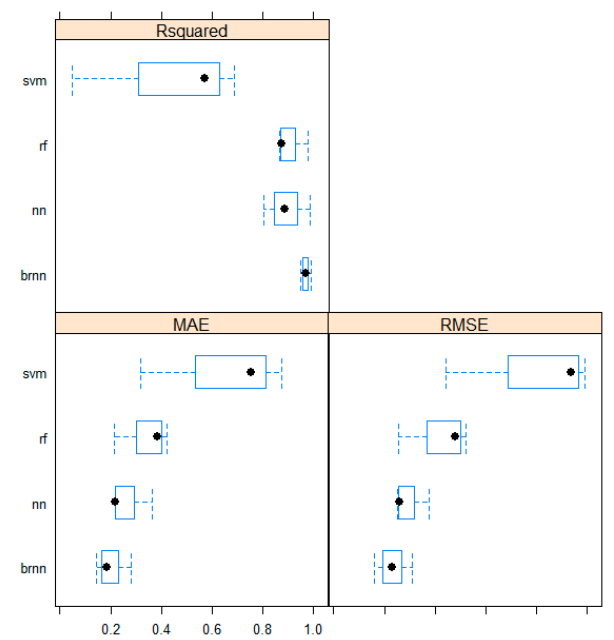

(b)

Figure 4. (a) Model performance of the indoles set; (b) Model performance of the lactones set.

\section{2}

163

\subsection{Descriptor Selection}

The $r f e$ ( ) function was used to to differentiate performance of a molecule based upon their unique set of molecular descriptors. To find the a proper size of descriptor set, a recursive function in $\mathrm{R}$ was used to test how accuracy changes with the number of descriptors. Accuracy descreased with more descriptors processed, and increased by focusing on the top twenty-five important descriptors. These relationships can be seen in the Figure 5.

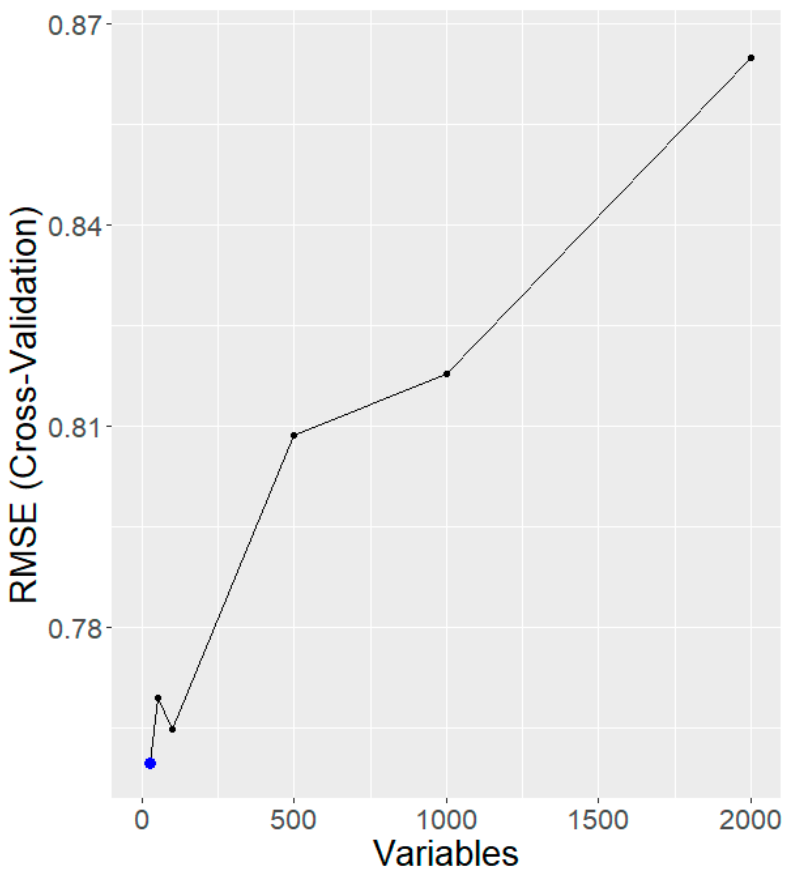

(a)

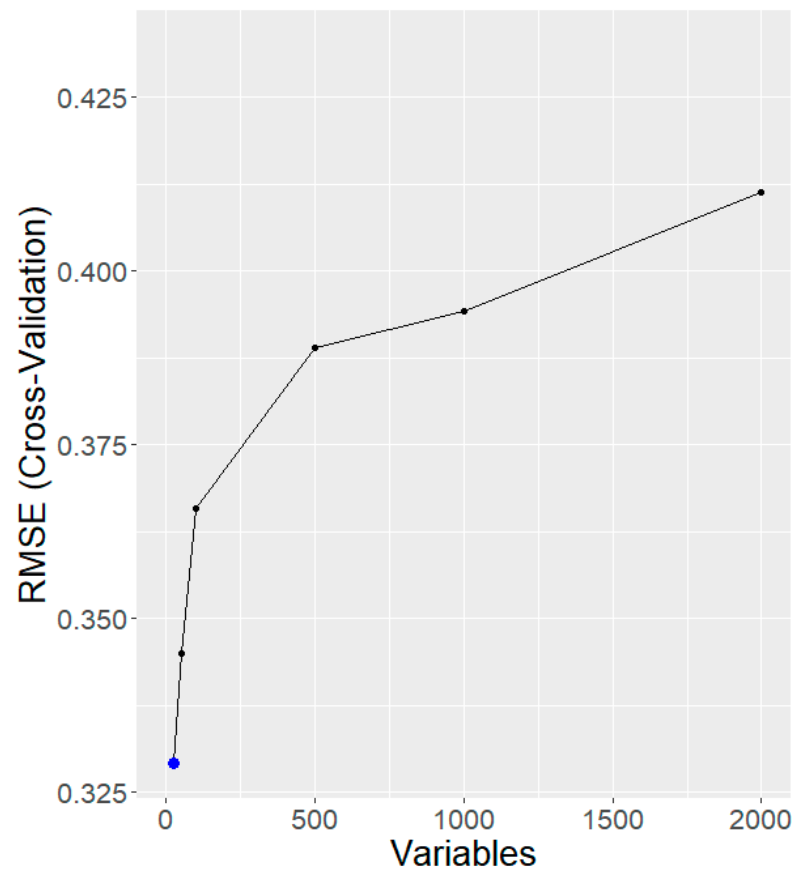

(b)

Figure 5. RMSE increased observed though more descriptors analyzed by RFE (a) in the indoles set; (b) in the lactones set. 
171

172

173

174

175

176

177

178

179

180

181

Each class of molecules have different important descriptors identified by the rfe ( ). Many descriptors are much more than simple counting observations such as how many oxygen atoms are present in the molecule. Some descriptors are used to evalulate the topology of the molecules and require matrix calculations. To explain what these desciptors mean, a brief overview of graph theory is required. Graph theory is a mathematics approach to measure the edges and vertices of complex geometries and can be applied in describing molecular structures [18]. In Chemical Graph Theory, the authors explain how matrices can be used to estimate the distances between atoms and bonds in the molecule. The topologies of the chemical structure have much to do with the conformations seen in binding interactions as well their rigidity in these positions. Table 2 and 3 describe an index of selected descriptors and their definitions.

Table 2. indole descriptors found by the $r f e$ () function .

\begin{tabular}{|c|c|}
\hline Descriptor & Name \\
\hline VE3sign_Dz(p) & $\begin{array}{l}\text { logarithmic coefficient sum of the last eigenvector from Barysz matrix } \\
\text { weighted by polarizability }\end{array}$ \\
\hline SpMin1_Bh(e) & $\begin{array}{c}\text { smallest eigenvalue n. } 1 \text { of Burden matrix weighted by Sanderson } \\
\text { electronegativity }\end{array}$ \\
\hline SpMin1_Bh(v) & smallest eigenvalue $n .1$ of Burden matrix weighted by Van der Wal's volume \\
\hline
\end{tabular}

182

Table 3. lactone descriptors found by the $r f e($ ) function .

\begin{tabular}{|c|c|}
\hline Descriptor & Name \\
\hline Eig15_AEA.ed. & $\begin{array}{l}\text { eigenvalue n. } 15 \text { from augmented edge adjacency mat. weighted by edge } \\
\text { degree }\end{array}$ \\
\hline MWC08 & molecular walk count of order 8 \\
\hline SpPosA_Dt & normalized spectral positive sum from detour matrix \\
\hline
\end{tabular}

183 Definitions of these descriptors rely on distance matrices used to measure the shape and topology. 184 Using Molecular Descriptors for Chemoinformatics as a guidebook for these descriptors can serve as 185 assistance for understanding the descriptors. By observing the relationships between a molecule 186 binding and its structural motifs, description-based guidelines be generated to show non-intuitive 187 relationships. The molecules classified as indoles had important molecules descriptions that related 188 to binding, shown in the Figure 6. 


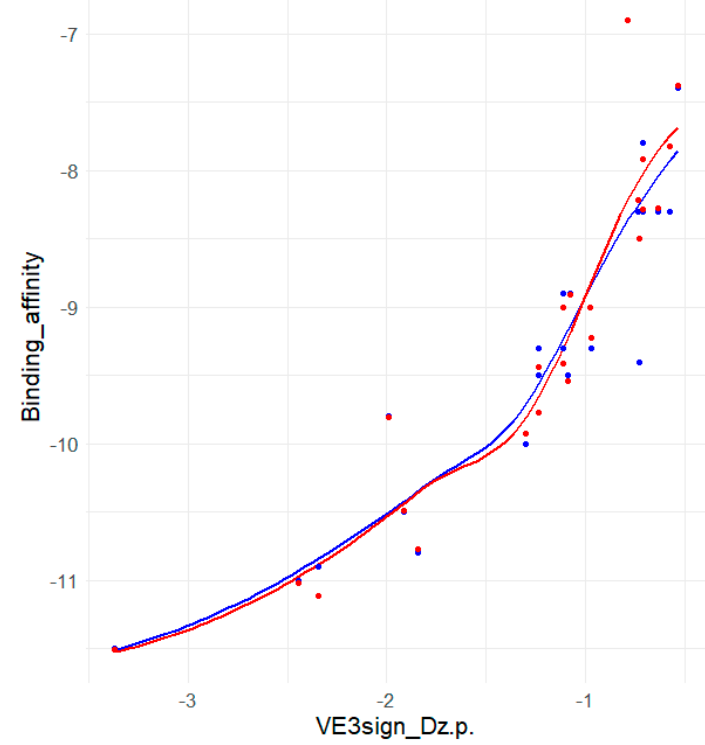

(a)

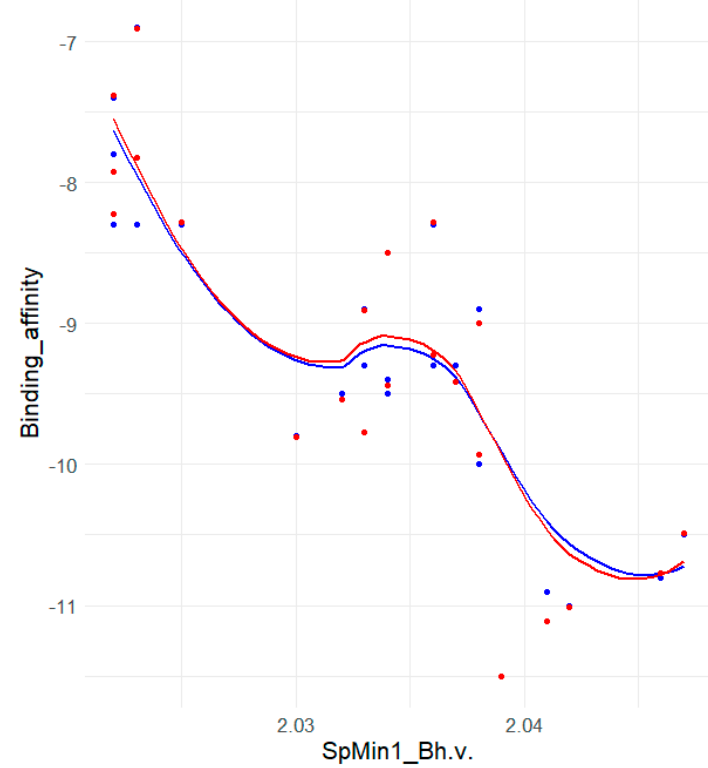

(c)

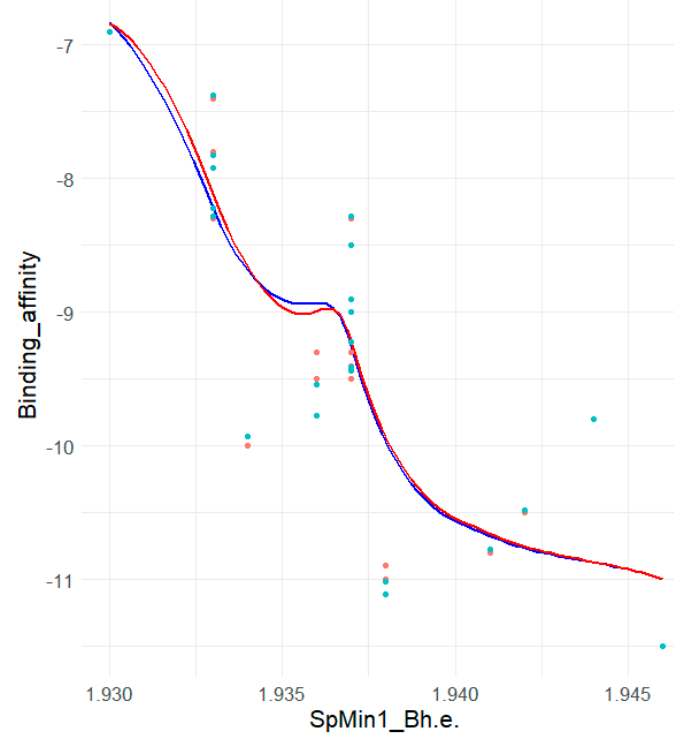

(b)

Figure 6. Relationships between binding affinity $(\mathrm{kJ} / \mathrm{mole})$ and molecular descriptions of the indoles set based on the descriptor; (a) VE3sign_Dz(p); (b) SpMin1_Bh(e); (c) SpMin1_Bh(e); data appearing in red was calculated by neural networks while data in blue was generated through AutoDock.

The relationship between descriptors and molecules tend to group the molecules in different sets based on topographical features. Through deduction one can uncover generalized rules for binding. The descriptor VE3sign_Dz(p) has a positive correlation with binding affinity while the descriptors, SpMin1_Bh(e) and SpMin1_Bh(v) have a negative correlation with binding affinity for the indole-type molecules. 
201 Groupings of descriptor data that account for the high binding affinity characteristics of selected molecules can be used to establish criteria for high-binding indoles. The criteria for high-binding (a binding affinity below $-9.5 \mathrm{~kJ} / \mathrm{mole}$ ) indoles is as follows;

The same comparison between descriptors and binding affinity was made with the lactones data and can be seen in Figure 7 .

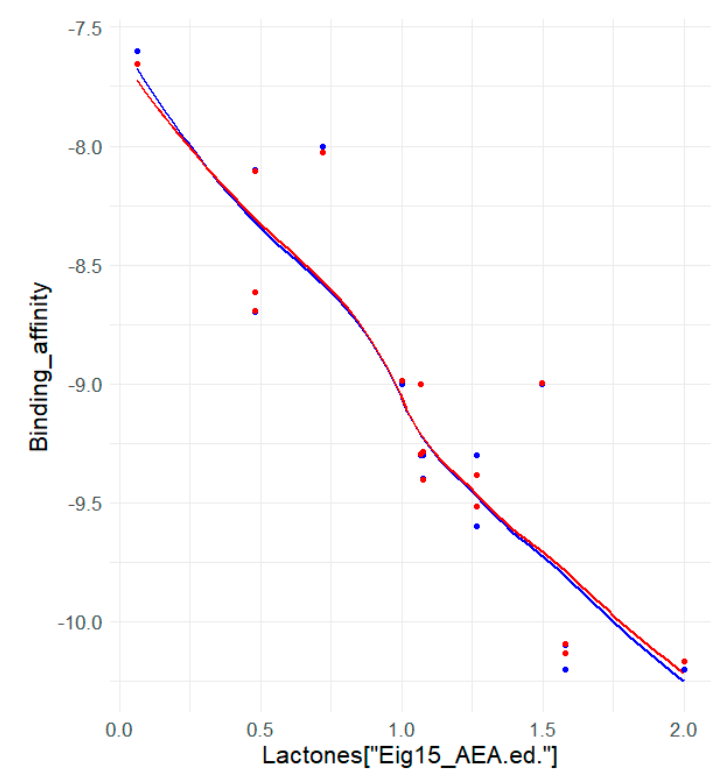

(a)

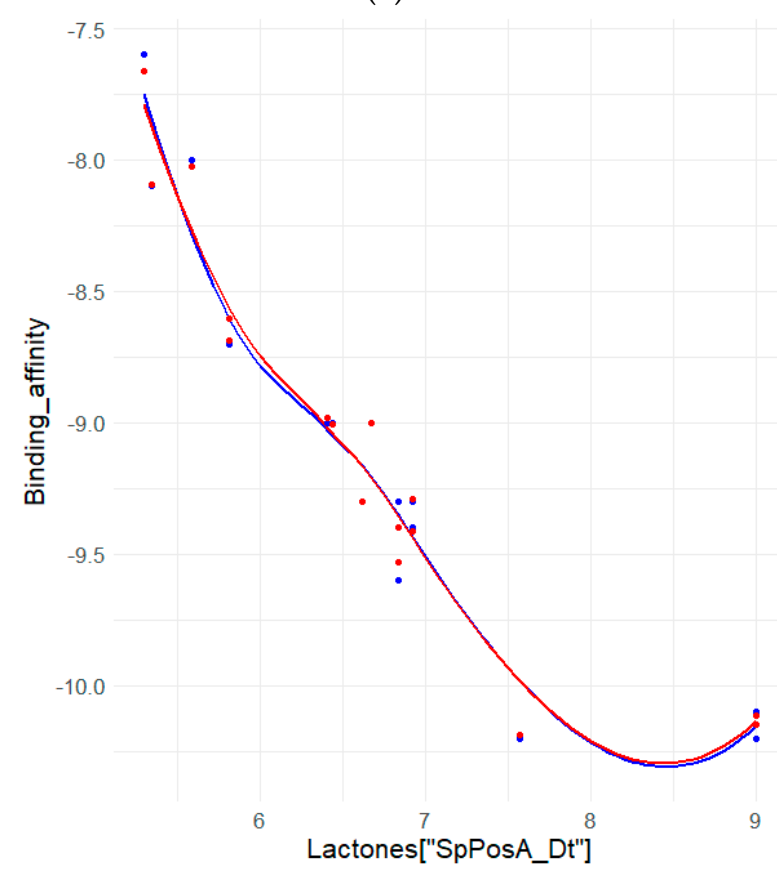

(c)

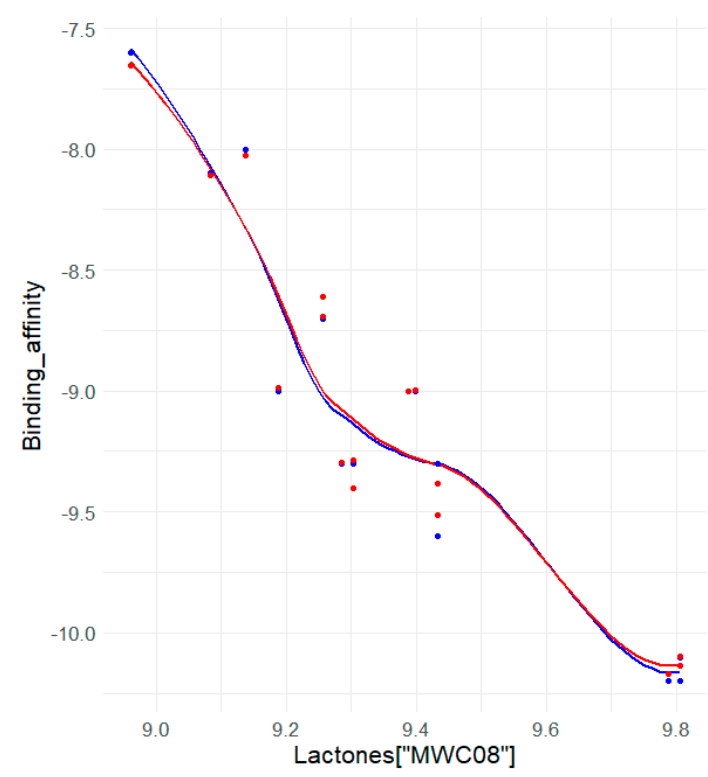

(b)

Figure 7. Relationships between binding affinity $(\mathrm{kJ} / \mathrm{mole})$ and molecular descriptions of the lactones set based on the descriptor; (a) Eig15_AEA; (b) MWC08; (c) SpPosA_Dt; data appearing in red was calculated by neural networks while data in blue was generated through AutoDock. 
The descriptors Eig15_AEA, MWC08, and SpPosA_Dt all have negative correlations with binding affinity for the lactone-type molecules. Groupings of descriptor data that account for the high binding affinity characteristics of selected lactones can be used to establish criteria like those generated from the indoles set. The criteria for high-binding (a binding affinity below -9.5 $\mathrm{kJ} / \mathrm{mole}$ ) lactones is as follows;

- $\quad$ MWC08 $>9.5$

- $\quad$ Eig15_AEA(ed) $>1.5$

- $\quad$ SpPosA_Dt $>7.5$

\subsection{Neural Network Performance}

BRANN models were trained with only $70 \%$ of the molecules and the test set of molecules were used to validate model prediction. Results of the test set were computated with the predict.train () function in caret, letting the model interpret new testing data for predictions of new compounds. A comparison of the test values and predictions the model makes can be seen in Figure 8. Values for predicted binding can be found in Appendix B.

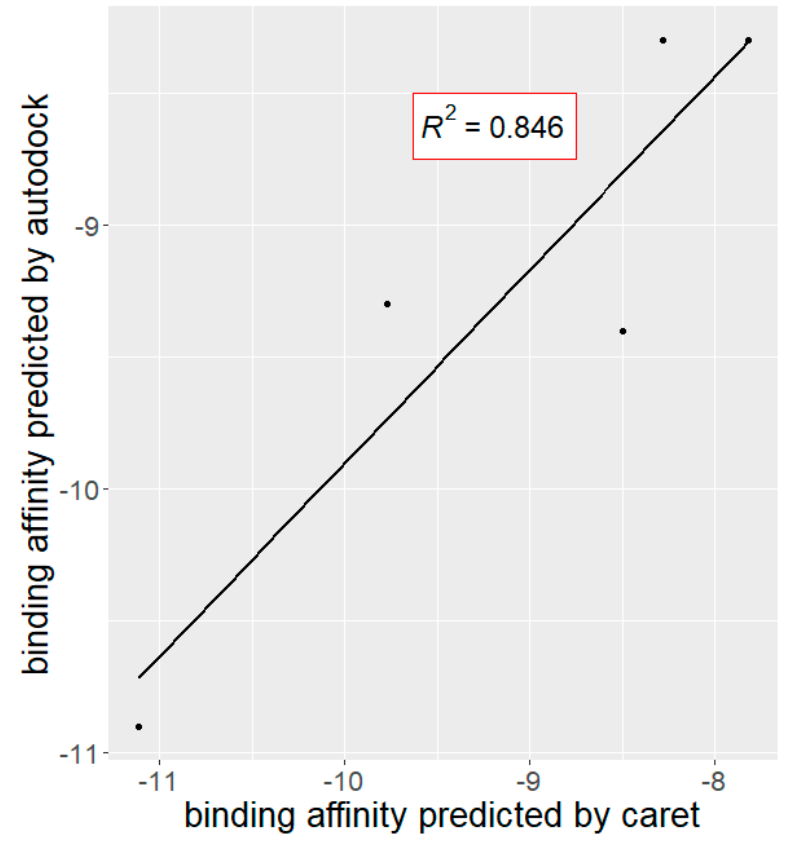

(a)

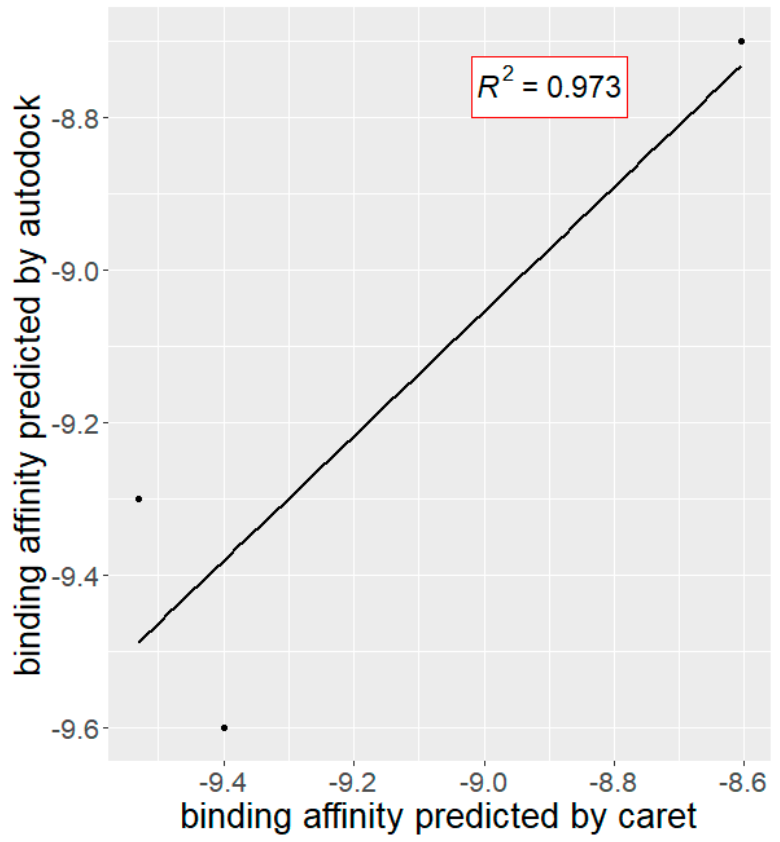

(b)

Figure 8, (a) Comparison of the indole set for validation of the its models prediction $\left(\mathrm{R}^{\wedge} 2=0.875\right.$, RMSE $=0.495$, units in $\mathrm{kJ} / \mathrm{mole}$ ); (b) Comparison of the Lactone set for validation of the its models prediction $\left(\mathrm{R}^{\wedge} 2=0.873, \mathrm{RMSE}=0.189\right.$, units in $\left.\mathrm{kJ} / \mathrm{mole}\right)$

One can also use the caret predict function to compare the training and testing set, to observe results of predictions across the entire dataset. The comparison between all predictions can be seen in Figure 9. Although this data in combined from 2 different models, it shows relative performance of prediction for both classes of molecules' binding affinity. 


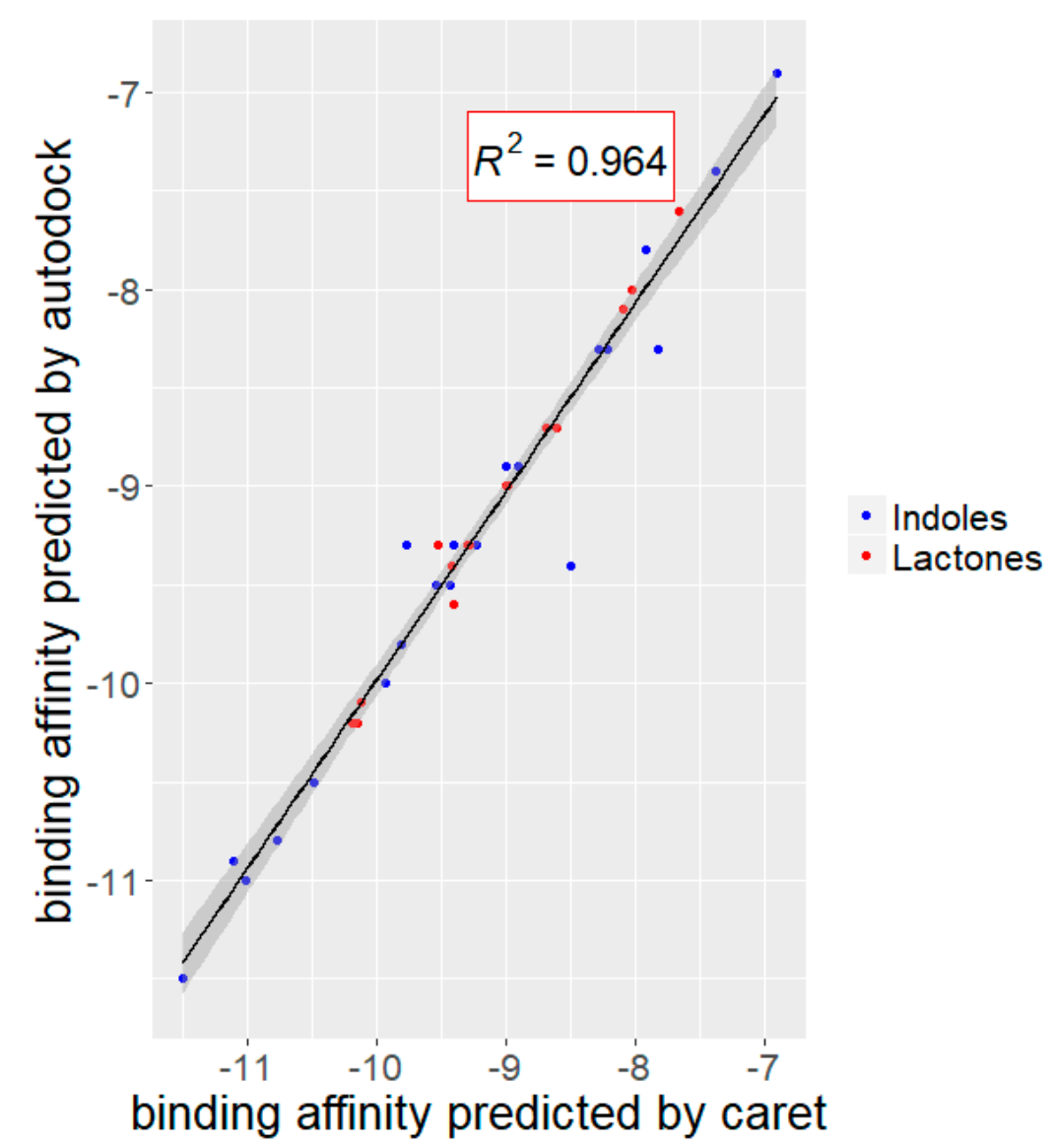

Figure 9. Comparison all molecules $\left(\mathrm{R}^{\wedge} 2=0.961, \mathrm{RMSE}=0.211\right.$, units in $\left.\mathrm{kJ} / \mathrm{mole}\right)$

While the criteria for high-binding QSIs seen in section 3.2 are good guidelines for machine learning prediction of binding, functional design of these molecules involves structural guidelines. Figure 10 and 11 show structures of the high binding molecules from each class along with key structural features of the molecules that contribute to their binding interaction with QS receptors.

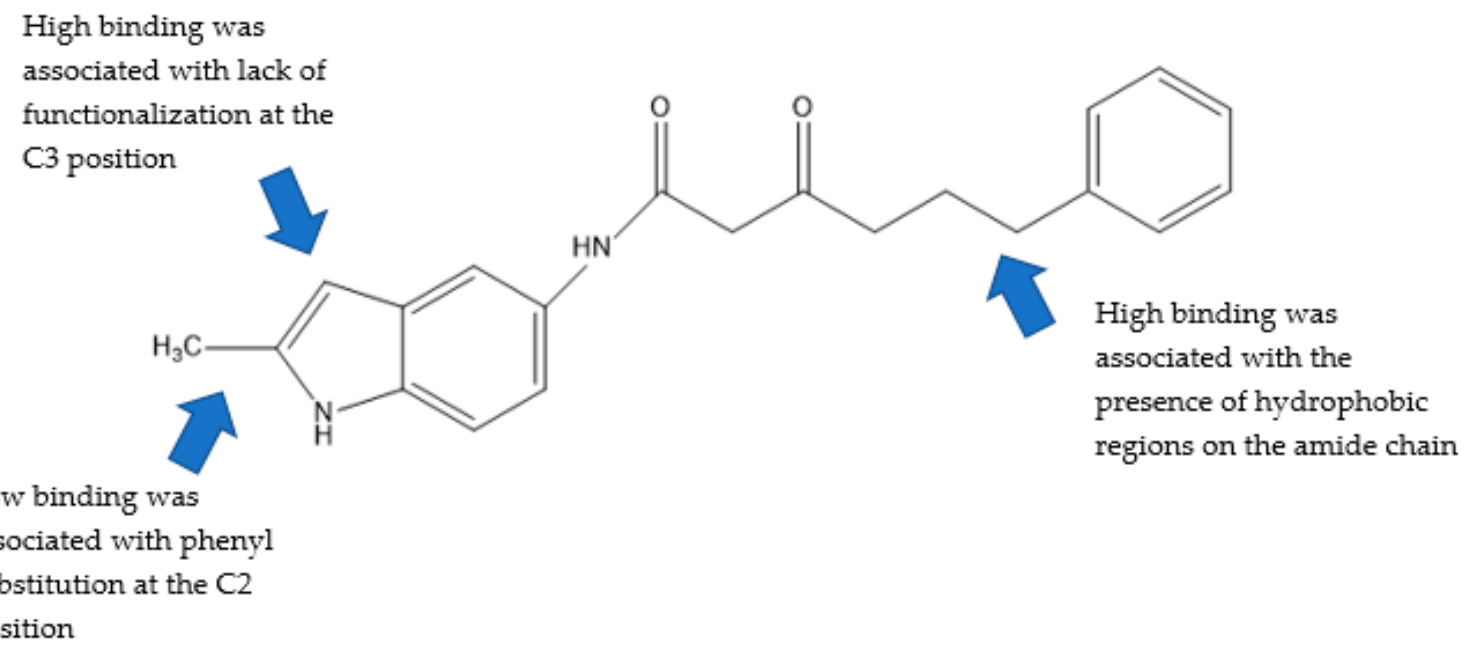

Figure 10. Key structural features of indole 16. 


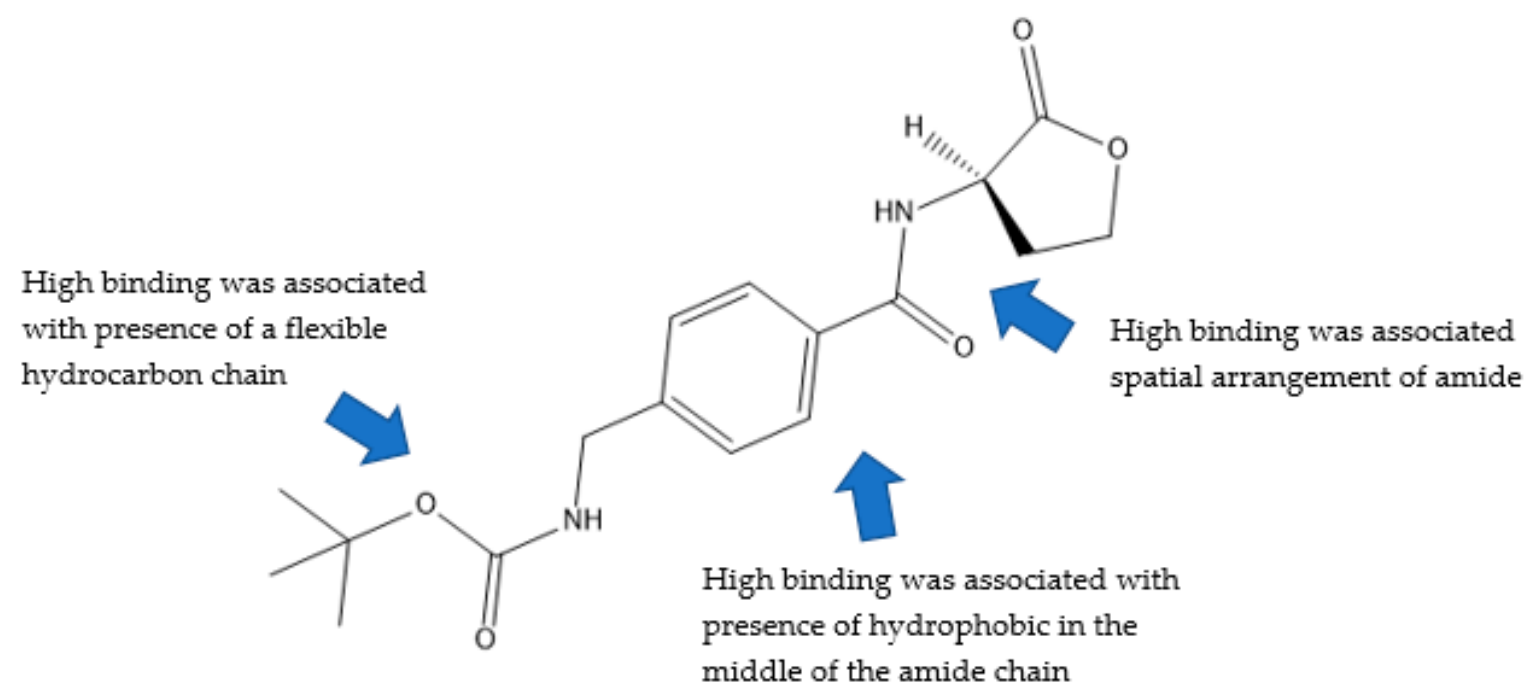

Figure 11. Key structural features of lactone 4

\section{Discussion}

Machine learning techniques like BRANNs for QSAR datasets allow for quick identification of the biochemical molecular design rules guiding complex protein interactions. Structural and topographical data for molecules provide insight about their function, as well as the underlying mechanisms of signaling events such as quorum sensing.

Quorum sensing research currently relies on culturing a model species in the laboratory and testing how well new inhibitors change the genotype of the bacteria. The testing assay relies on a fluorescent marker that is activated through expression of the reporter protein. While this methodology measures the change directly, it does not account for the intricacies of real world problems in inhibiting biofilms.

At the beginning of this project, we attempted to use results of fluorescent assays as our dependent variable instead of binding affinity. Fluorescence results as seen in the work of Nath et al. are a direct measure of how well the new genes are activated by QSIs [5]. While an assay measurement is indeed a direct measure of the biochemical effect, each research group or set of source data uses a different negative control for relative fluorescence, meaning that different results are not comparable across studies, a key setback when attempting to discover unifying design rules and generalized models of performance. Using binding affinities predicted in silico by AutoDock is useful for comparing binding-based design to structure-based design. Machine learning and structurebased design are complementary tools for discovering new knowledge about binding interactions. Bacteria use the QS signaling process as a common language and the syntax of this language is more complex than what can be observed through biology methodologies and experimentation. The work presented by So and Karplus represents one such attempt at applying high-throughput methodologies in QSAR studies[18]. Molecules that improve meaning of the signaling language, like indoles, should be compared to those of other classes, and other topologies. Screening for similar protein interactions that bacteria share signaling processes for could prove effective at gaining knowledge about other signaling cascades that regulate the bacterial genome.

Discovering new alternatives or designing functional improvements in biological systems is hard. An extensive amount of time is spent designing methodologies, synthesizing new molecules, and analyzing results. The work presented in this study shows one such attempt at apply design tools towards the discovery of guidelines for strong QSIs. Knowing this information, it enables more conclusions to be drawn about QS solutions for fighting biofilms. 
Acknowledgments: This work was supported in part through the Bill and Linda Frost Fund at Cal Poly San Luis Obispo. B.S. was selected as a Frost Research Fellow in the Frost Summer 2017 Undergraduate Research Program.

Author Contributions: B.S. and E.S. designed the experiment; B.S. wrote scripts and performed analysis; E.S. contributed software and knowledge; B.S. wrote the paper; B.S. and E.S. edited the paper.

Conflicts of Interest: The authors declare no conflict of interest.

.

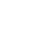

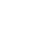

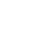

(

(1)

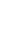




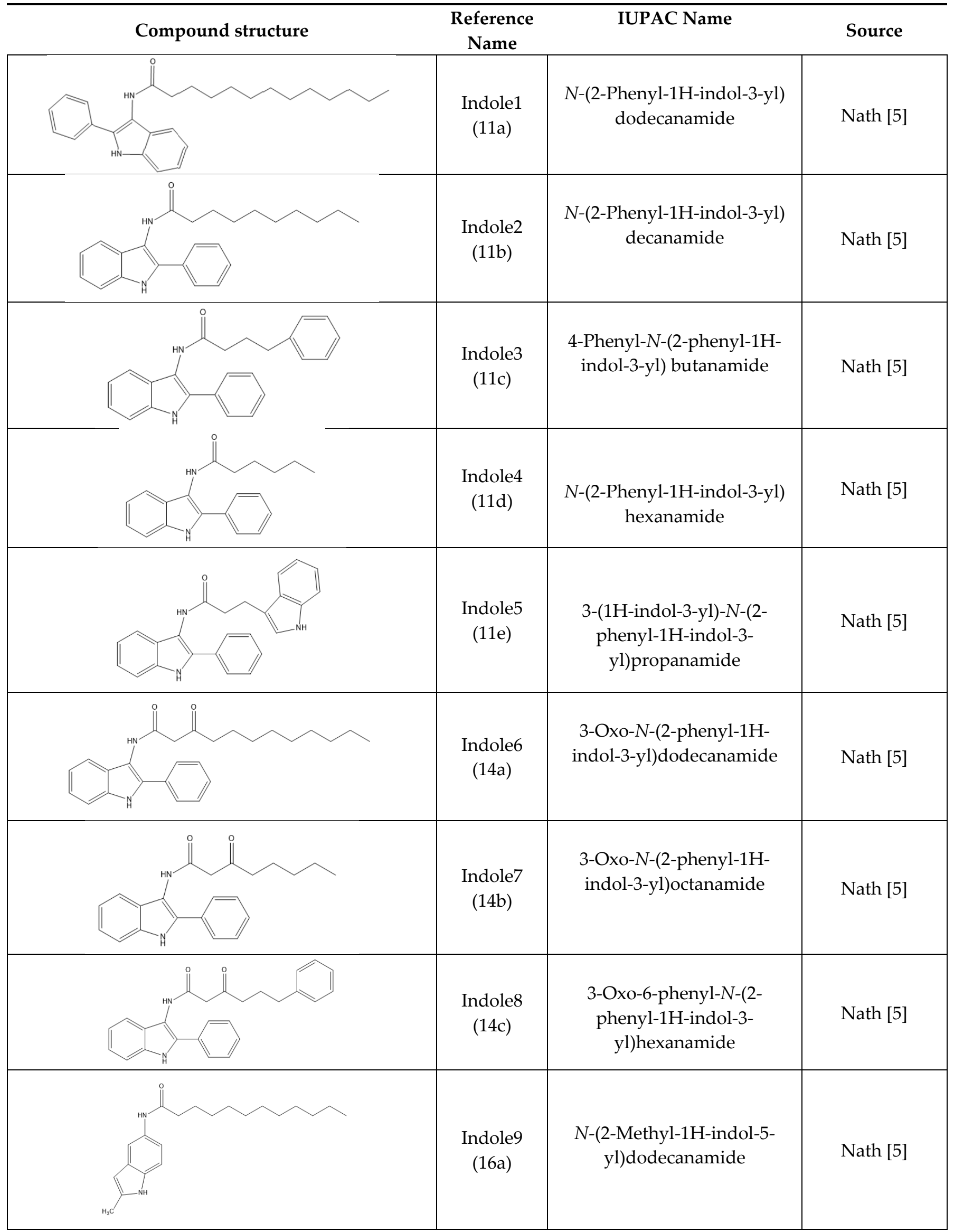




\begin{tabular}{|c|c|c|c|}
\hline Compound structure & $\begin{array}{c}\text { Reference } \\
\text { Name }\end{array}$ & IUPAC Name & Source \\
\hline & $\begin{array}{l}\text { Indole10 } \\
\qquad(16 b)\end{array}$ & $\begin{array}{l}\text { N-(2-Methyl-1H-indol-5- } \\
\text { yl)decanamide }\end{array}$ & Nath [5] \\
\hline & $\begin{array}{l}\text { Indole11 } \\
\qquad(16 \mathrm{c})\end{array}$ & $\begin{array}{l}\text { N-(2-Methyl-1H-indol-5-yl)- } \\
\text { 4-phenylbutanamide }\end{array}$ & Nath [5] \\
\hline & $\begin{array}{l}\text { Indole12 } \\
\qquad(16 \mathrm{~d})\end{array}$ & $\begin{array}{c}N \text {-(2-Methyl-1H-indol-5- } \\
\text { yl)hexanamide }\end{array}$ & Nath [5] \\
\hline & $\begin{array}{l}\text { Indole13 } \\
\qquad(16 \mathrm{e})\end{array}$ & $\begin{array}{c}\text { 3-(1H-Indol-3-yl)-N-(2- } \\
\text { Methyl-1H-indol-5- } \\
\text { yl)propanamide }\end{array}$ & Nath [5] \\
\hline & $\begin{array}{l}\text { Indole14 } \\
\qquad(17 \mathrm{a})\end{array}$ & $\begin{array}{l}\text { N-(2-Methyl-1H-indol-5-yl)- } \\
\text { 3-oxododecanamide }\end{array}$ & Nath [5] \\
\hline & $\begin{array}{l}\text { Indole15 } \\
\qquad(17 \mathrm{~b})\end{array}$ & $\begin{array}{l}\text { N-(2-Methyl-1H-indol-5-yl)- } \\
\text { 3-oxodooctanamide }\end{array}$ & Nath [5] \\
\hline & $\begin{array}{l}\text { Indole16 } \\
\qquad(17 \mathrm{c})\end{array}$ & $\begin{array}{l}N \text {-(2-Methyl-1H-indol-5-yl)- } \\
\text { 3-oxo-6-phenylhexanamide }\end{array}$ & Nath [5] \\
\hline & $\begin{array}{l}\text { Indole17 } \\
\qquad(19)\end{array}$ & 1H-Indol-7-amine & Nath [5] \\
\hline & $\begin{array}{l}\text { Indole18 } \\
\qquad(20 \mathrm{a})\end{array}$ & $\begin{array}{l}N-(1 \mathrm{H}-\text { Indol-7- } \\
\text { yl)decanamide }\end{array}$ & Nath [5] \\
\hline
\end{tabular}




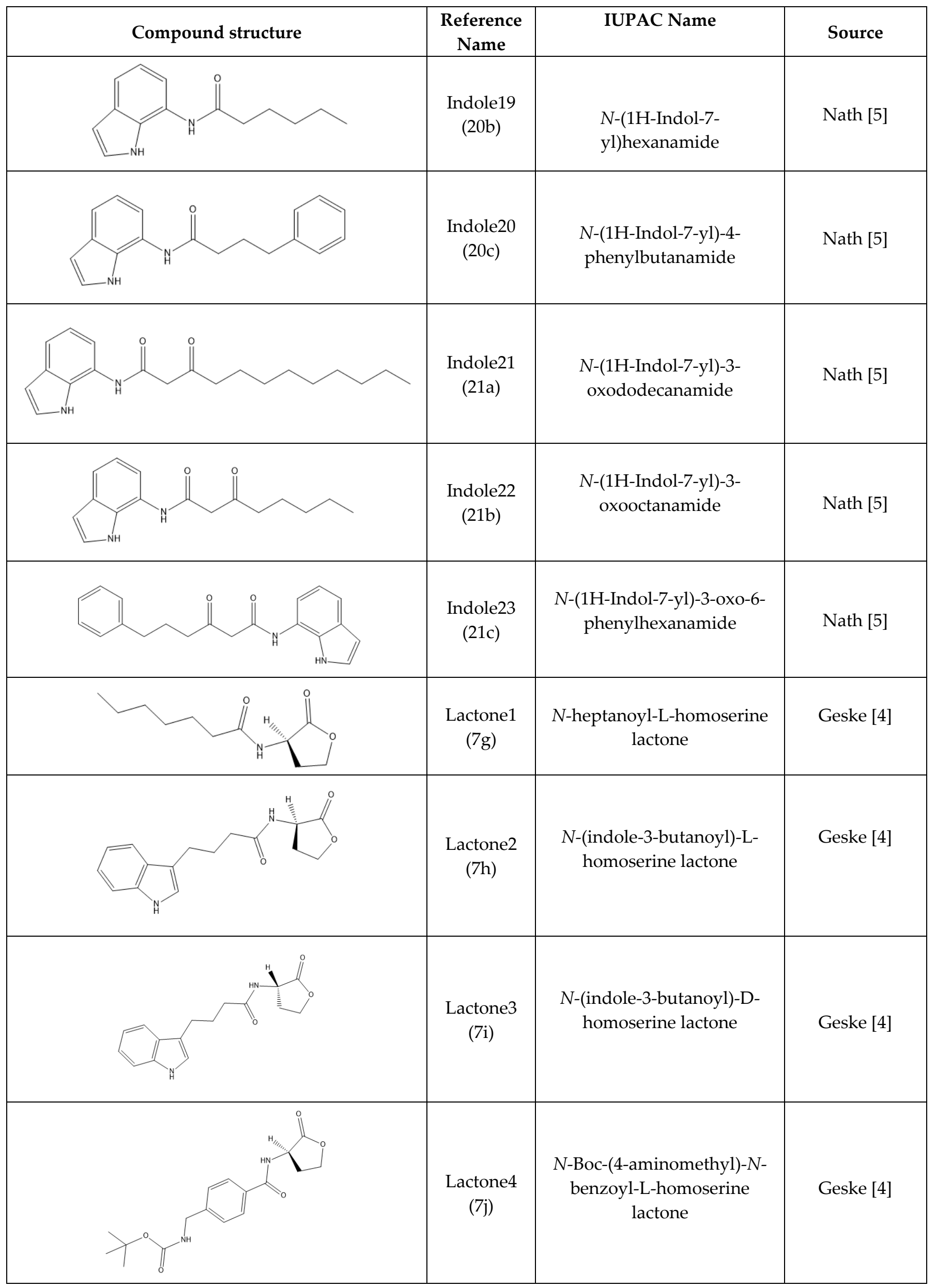




\begin{tabular}{|c|c|c|c|}
\hline Compound structure & $\begin{array}{c}\text { Reference } \\
\text { Name }\end{array}$ & IUPAC Name & Source \\
\hline & $\begin{array}{l}\text { Lactone5 } \\
\quad(7 \mathrm{k})\end{array}$ & $\begin{array}{c}N \text {-(2-cyclo-entene-1- } \\
\text { acetonoyl)-L-homoserine } \\
\text { lactone }\end{array}$ & Geske [4] \\
\hline & $\begin{array}{l}\text { Lactone6 } \\
\qquad(71)\end{array}$ & $\begin{array}{c}N \text {-(2-cyclo-entene-1- } \\
\text { acetonoyl)-D-homoserine } \\
\text { lactone }\end{array}$ & Geske [4] \\
\hline & $\begin{array}{l}\text { Lactone7 } \\
\qquad(7 \mathrm{~m})\end{array}$ & $\begin{array}{l}\text { N-Boc-aminocapranoyl-L- } \\
\text { homoserine lactone }\end{array}$ & Geske [4] \\
\hline & $\begin{array}{l}\text { Lactone8 } \\
\qquad(7 n)\end{array}$ & $\begin{array}{l}N \text {-monoethyl fumaroyl-L- } \\
\text { homoserine lactone }\end{array}$ & Geske [4] \\
\hline & $\begin{array}{l}\text { Lactone9 } \\
\qquad(7 \mathrm{o})\end{array}$ & $\begin{array}{l}\mathrm{N}-(4- \\
\text { bromophenylacetanoyl)-L- } \\
\text { homoserine lactone }\end{array}$ & Geske [4] \\
\hline & $\begin{array}{l}\text { Lactone10 } \\
\text { (7p) }\end{array}$ & $\begin{array}{l}N \text {-(trans-cinamoyl)-L- } \\
\text { homoserine lactone }\end{array}$ & Geske [4] \\
\hline & $\begin{array}{l}\text { Lactone11 } \\
\qquad(7 q)\end{array}$ & $\begin{array}{l}N \text {-(4-phenylbutanoyl)-L- } \\
\text { homoserine lactone }\end{array}$ & Geske [4] \\
\hline & $\begin{array}{l}\text { Lactone12 } \\
\text { (7r) }\end{array}$ & $\begin{array}{l}N \text {-(4-phenylbutanoyl)-D- } \\
\text { homoserine lactone }\end{array}$ & Geske [4] \\
\hline & $\begin{array}{l}\text { Lactone13 } \\
\text { (8f) }\end{array}$ & $\begin{array}{l}\text { N-(3-oxo-3- } \\
\text { phenylpropanoyl)-L- } \\
\text { homoserine lactone }\end{array}$ & Geske [4] \\
\hline & $\begin{array}{l}\text { Lactone14 } \\
(8 \mathrm{~g})\end{array}$ & $\begin{array}{l}\text { N-(3-oxo-3- } \\
\text { phenylpropanoyl)-D- } \\
\text { homoserine lactone }\end{array}$ & Geske [4] \\
\hline
\end{tabular}




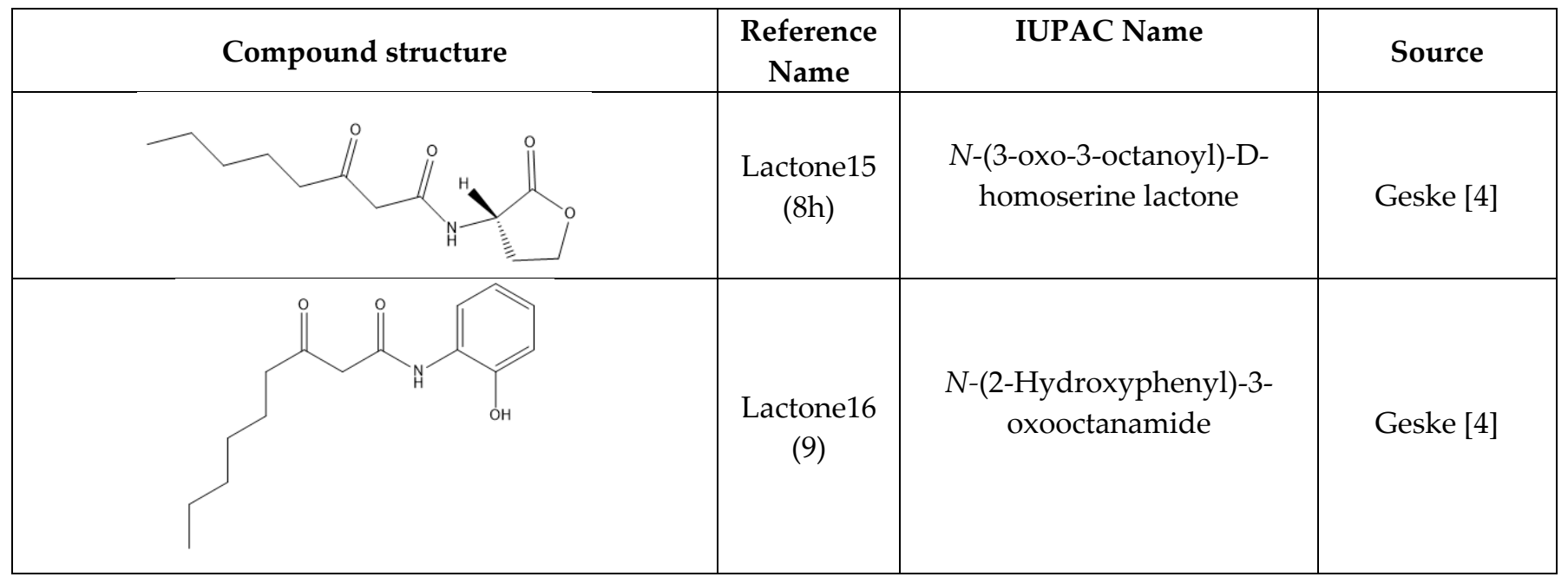

\begin{tabular}{|c|c|c|}
\hline Reference Name & $\begin{array}{c}\text { Binding Affinity predicted by } \\
\text { autodock ( } \mathrm{kJ} / \text { mole })\end{array}$ & $\begin{array}{c}\text { Binding Affinity predicted by } \\
\text { caret ( } \mathrm{kJ} / \text { mole })\end{array}$ \\
\hline Indole1 & -8.3 & -8.302988 \\
\hline Indole2 & -8.3 & -7.988344 \\
\hline Indole3 & -8.9 & -8.937417 \\
\hline Indole4 & -7.4 & -7.417268 \\
\hline Indole5 & -9.8 & -9.795367 \\
\hline Indole6 & -8.3 & -8.325539 \\
\hline Indole7 & -7.8 & -7.851770 \\
\hline Indole8 & -10.0 & -9.936407 \\
\hline Indole9 & -9.3 & -9.377961 \\
\hline Indole10 & -9.3 & -9.253377 \\
\hline Indole11 & -10.8 & -10.831108 \\
\hline Indole12 & -9.4 & -8.554745 \\
\hline Indole13 & -11.5 & -11.433772 \\
\hline Indole14 & -9.3 & -9.988707 \\
\hline Indole15 & -9.5 & -9.494719 \\
\hline Indole16 & -10.9 & -11.448594 \\
\hline Indole17 & -6.9 & -6.926807 \\
\hline Indole18 & -9.0 & -9.035383 \\
\hline Indole19 & -8.3 & -8.280500 \\
\hline Indole20 & -10.5 & -10.444431 \\
\hline Indole21 & -9.5 & -9.462499 \\
\hline Indole22 & -8.9 & -8.951946 \\
\hline Indole23 & -11.0 & -10.992407 \\
\hline Lactone1 & -7.6 & -7.64831 \\
\hline Lactone2 & -10.1 & -10.118163 \\
\hline Lactone3 & -10.2 & -10.138430 \\
\hline Lactone4 & -10.2 & -10.188640 \\
\hline
\end{tabular}




\begin{tabular}{|c|c|c|}
\hline Reference Name & $\begin{array}{c}\text { Binding Affinity predicted by } \\
\text { autodock( kJ/mole) }\end{array}$ & $\begin{array}{c}\text { Binding Affinity predicted b } \\
\text { y caret( kJ/mole) }\end{array}$ \\
\hline Lactone5 & -8.7 & -8.583115 \\
\hline Lactone6 & -8.7 & -8.678089 \\
\hline Lactone7 & -9.0 & -8.990841 \\
\hline Lactone8 & -8.1 & -8.103228 \\
\hline Lactone9 & -9.0 & -9.013618 \\
\hline Lactone10 & -9.3 & -9.310404 \\
\hline Lactone11 & -9.3 & -9.272423 \\
\hline Lactone12 & -9.4 & -9.425550 \\
\hline Lactone13 & -9.3 & -9.487820 \\
\hline Lactone14 & -9.6 & -9.460026 \\
\hline Lactone15 & -8.0 & -8.043582 \\
\hline Lactone16 & -9.0 & -8.979812 \\
\hline
\end{tabular}

\section{References}

311 1. Bakke, R.; Kommedal, R.; Kalvenes, S. Quantification of biofilm accumulation by an optical approach. J. Microbiol. Methods 2001, 44, 13-26; DOI: 10.1016/S0167-7012(00)00236-0.

2. Soulère, L.; Marine F.; Yves Q.; Alain D. Exploring the Active Site of Acyl Homoserine LactonesDependent Transcriptional Regulators with Bacterial Quorum Sensing Modulators Using Molecular Mechanics and Docking Studies. Journal of Molecular Graphics and Modelling. 2007, 581-590; DOI: 10.1016/j.jmgm.2007.04.004.

3. Ni, N.; Minyong L.; Junfeng W.; and Binghe W. Inhibitors and Antagonists of Bacterial Quorum Sensing. Medicinal Research Reviews, 2009. 65-154; DOI:10.1002/med.20145.

4. Geske, G.D.; Rachel J.W.; Adam P.S.; and Helen E.B. Small Molecule Inhibitors of Bacterial Quorum Sensing and Biofilm Formation. Journal of the American Chemical Society, 127, 2005, 12762-63; DOI:10.1021/ja0530321.

5. Nath, B.N.; Kutty, S.K.; Barraud, N.; Iskander, G.M.; Griffith, R.; Rice, S.A.; Willcox, M.; Black, D.S.; Kumar, N. Indole-Based Novel Small Molecules for the Modulation of Bacterial Signaling Pathways. Org. Biomol. Chem. 13, 3, 2015. 925-37. DOI:10.1039/C4OB02096K.

6. Mitchell, J. B. Machine Learning Methods in Chemoinformatics. Wiley Interdisciplinary Reviews: Computational Molecular Science 4, 5, 2014. 468-81. DOI:10.1002/wcms.1183.

7. R Core Team. R: A language and environment for statistical computing. R Foundation for Statistical Computing, 2007 Vienna, Austria. https://www.R-project.org

8. Kuhn, M.; Wing, J.; Weston, S.; Williams, A.; Keefer, C.; Engelhardt, A. Caret: Classification and Regression Training. https://Cran.R-Project.Org/Package=Caret,

2012. DOI:10.1053/j.sodo.2009.03.002.

9. Perkin Elmer Informatics, Chemdraw, 2012

10. O'Boyle, N.M.; Banck, M.; James, C.A.; Morley, C.; Vandermeersch, T.; Hutchison, G.R.; Open Babel: An Open Chemical Toolbox. Journal of Cheminformatics 3, 10 2011. DOI:10.1186/1758-29463-33. 
336 11. Andrea, M.; Consonni, V.; Pavan, M.; Todeschini, R. Dragon software: An easy approach to molecular descriptor calculations. Match 56, 2, 2006. 237-248.

12. Zou, Y.; Nair, S.K. LasR-OC12 HSL Complex. PDB ID: 3IX3 TO BE PUBLISHED, n.d. DOI:10.2210/PDB3IX3/PDB.

13. Berman, H.M.; Westbrook, J.; Feng, Z.; Gilliland, G.; Bhat, T.N.; Weissig, H.; Shindyalov, I.N.; Bourne P.E. The Protein Data Bank Nucleic Acids Research, 28: 2000. 235-242.

14. Morris G.M.; Dallakyan, S. AutoDock. 02-27 1, 2013. 15-45.

15. Trott, O.; Olson. A.J. AutoDock Vina. J. Comput. Chem. 31 2010. 445-61. DOI:10.1002/jcc.21334.

16. MacKay, D. J. C. A Practical Bayesian Framework for Backprop Networks. Neural Comput. 4 1992. $415-447$

17. Winkler, D.A. The Role of Quantitative Structure--Activity Relationships (QSAR) in Biomolecular Discovery. Briefings in Bioinformatics 3, 2002. 73-86. DOI:10.1093/bib/3.1.73.

18. Estrada, E.; Bonchev, D. Chemical Graph Theory. 1538-1558. 10.1201/b16132-92.

19. So, S.S.; Karplus, M. Evolutionary Optimization in Quantitative Structure-Activity Relationship: An Application of Genetic Neural Networks. Journal of Medicinal Chemistry 39 1996. 1521-30. DOI:10.1021/jm9507035.

20. Todeschini, R.; Consonni, V.; Mannhold, R.; Kubinyi, H.; Folkers, G. Molecular Descriptors for Chemoinformatics. Wiley-VCH, 2009. 